\title{
Primeira Oficina Coletiva FNEPAS na Regional São Paulo
}

\section{informes}

\section{fnepas}

Sob o tema "Integralidade e qualidade na formação e nas práticas em saúde: integrando formação, serviços e usuários" aconteceu no Instituto de Biociências da Unesp/Botucatu, em 24 e 25 de agosto de 2007, a Oficina Coletiva do Projeto do Fórum Nacional de Educação das Profissões na Área de Saúde - FNEPAS.

O FNEPAS é o resultado de uma articulação entre diversas entidades e associações ligadas ao ensino superior das profissões da saúde do nosso país. Busca contribuir para o processo de mudança na graduação, partilhando da concepção de integralidade na atenção e formação em saúde. É considerado uma estratégia da Política Nacional de Educação Permanente, com apoio da Secretaria de Gestão do Trabalho e da Educação em Saúde (SGTES/ Ministério da Saúde) e do Ministério da Educação.

O evento de Botucatu teve como objetivos: proporcionar o compartilhamento, entre as profissões, dos diferentes olhares e das formulações a respeito dos desafios da implementação das diretrizes curriculares nos cursos de graduação da área da saúde; criar uma oportunidade para a reflexão conjunta sobre o tema da integralidade, considerado central para a inovação das práticas e da formação em saúde; construir um repertório mínimo compartilhado que subsidie a realização de outros movimentos de aproximação regional entre as diferentes profissões da saúde.

A oficina foi organizada com a parceria FNEPAS, Conselho de Curso de Graduação em Medicina e Núcleo de Apoio Pedagógico da FMB - UNESP. Participaram ativamente do processo de organização docentes, técnicos e alunos da Faculdade de Medicina, Faculdade de Medicina Veterinária e Zootecnia, do Instituto de Biociências e Centro Acadêmico Pirajá da Silva, além de profisisonais do próprio FNEPAS.

Foram mais de 160 inscritos das 14 profissões da área da saúde (Biologia, Biomedicina, Educação Física, Enfermagem, Farmácia, Fisioterapia, Fonoaudiologia, Medicina, Medicina Veterinária, Nutrição, Odontologia, Psicologia, Serviço Social e Terapia Ocupacional) de instituições públicas e privadas das regiões de Bauru e Botucatu, com representação de docentes, discentes, profissionais da saúde, do controle social e de gestão. Na abertura do evento autoridades da UNESP, prefeitura de Botucatu e do Fnepas enfatizaram o apoio às metas do Fnepas e a necessidade de trabalho intersetorial e interdisciplinar.

No período da manhã, o Prof. Ricardo Burg Ceccim, da UFRS, coordenou a "Roda de Ativadores", resgatando a discussão e as propostas de ação sobre mudanças curriculares, com a participação dos profissionais que participaram do Curso de Especialização em Ativação de Processos de Mudança na Formação Superior de Profissionais de Saúde, da ENSP, Ministério da Saúde e REDE UNIDA. Foram apresentados nesta ocasião 11 trabalhos desenvolvidos na região. 
No período da tarde, a atividade "Conversando sobre Integralidade" incluiu a discussão de concepções teóricas sobre a temática da oficina, pelo prof. Ricardo Ceccim, dos aspectos da Educação Popular na atenção básica como processo de busca da integralidade, pela profa. Josely Rimoli, a integralidade e educação popular em saúde do ponto de vista da comunidade e o controle social, pela líder comunitária Remédios Mira Fernandes e considerações sobre os desafio da integralidade do ponto de vista discente, pleo aluno Pedro Tadao Hamamoto Filho, do curso de Medicina. Em seguida foram formados grupos de trabalho segundo a diversidade de setores e áreas, com intensa participação dos envolvidos e trocas de experiências inovadoras relacionadas à integralidade e à formação profissional, além da discussão de propostas concretas de ação relacionadas a diferentes instituições presentes. A atividade culminou com a elaboração de um documento preliminar sobre a discussão realizada e propostas de trabalho.

Entre as propostas de trabalho destaca-se a criação de um Conselho de Coordenadores dos Cursos do campus de Botucatu. Este Conselho deverá funcionar como ambiente de troca de experiências e desenvolvimento de projetos que envolvam conjuntamente professores e alunos dos diferentes cursos de graduação. Devido às características do campus, que conta com seis cursos da área da saúde (Medicina, Medicina Veterinária, Enfermagem, Nutrição, Ciências Biomédicas, Ciências Biológicas), é possível desenvolver atividades integradas de atenção a saúde nos seus mais diversos níveis. A existência de quatro cursos ligados às ciências agrárias (Medicina Veterinária, Zootecnia, Engenharia Agronômica e Engenharia Florestal) complementa este cenário, pois os profissionais desta área estão diretamente envolvidos com o desenvolvimento de processos sustentáveis de interação ambiental produtiva.

Além de ações locais, foi proposta a criação do Fórum de Coordenadores de Curso de Graduação da área da saúde da regional de Botucatu/Bauru, para discutir estratégias de implementação das diretrizes curriculares e desenvolvam projetos interinstitucionais.

A Oficina Coletiva do FNEPAS da regional Botucatu/Bauru foi encerrada em um clima de entusiasmo e comprometimento com as propostas apresentadas. Outras oficinas FNEPAS estão ocorrendo em todo o Estado de São Paulo e outras regiões do país e informações sobre esses eventos podem ser obtidas no site <http://www.fnepas.org.br>. Os interessados em manter as discussões sobre a temática da oficina na região de Botucatu/Bauru devem subscrever ao grupo fnepasbotucatu-subscribe@yahoogrupos.com.br

Vera Lúcia Garcia; fonoaudióloga; doutora em Distúrbios da Comunicação Humana; professora tutora, Fundação para o Desenvolvimento Médico Hospitalar. Botucatu, SP. <vlgarcia@uol.com.br>

João Carlos Pinheiro Ferreira; médico veterinário; doutor em Medicina Veterinária; professor, departamento de Reprodução Animal e Radiologia Veterinária, Faculdade de Medicia Veterinária e Zootecnia, Universidade Estadual Paulista/Unesp. Botucatu, SP. <jcferreira@fmvz.unesp.br>

Eliana Goldfarb Cyrino; médica; doutora; professora, departamento de saúde Pública, Faculdade de Medicina de Botucatu, Universidade Estadual Paulista/Unesp. Botucatu, SP. <ecyrino@fmb.unesp.br 